\title{
包头市 2016-2020 年工业危险废物数据分析
}

\section{Analysis of Industry Hazardous Waste in BaoTou in 2016-2020}

\author{
刘叶 \\ Ye Liu \\ 包头市固体废物监管中心 内蒙古 包头 014060 \\ Baotou Solid waste Control Centre BaoTou Inner Mongolia 014060
}

\begin{abstract}
摘 要: 包头市目前的工业危险废物产生量在全国名列前茅。随着经济迅速发展和国家对危险废物的分类更加细化， 2016-2020 年工业危险废物产生量逐年递增, 2016-2020 年期间产生量较上个 5 年(2010-2015 年)增长约 30 倍。在政府部门 的政策法规推动下, 以及危险废物市场自身不断发展壮大, 包头市危险废物经营单位利用处置能力大幅提升, 利用处置率一 直保持在较高水平, 整体较上个 5 年有明显提升。
\end{abstract}

\begin{abstract}
The industry hazardous waste production in BaoTou has come out in front of the whole country at the moment, which has been Increasing year by year.Besides, the production in 2016-2020 has increased of 30times than the last 5 years(2010-2015), because of the rapid development of economy and hazardous waste category detailed. At the same time, with the promulgation? of policies and regulations of the government, and the capacity for reuse and desposal of hazardous waste belongs to the management enterprises had advanced of big extent, reuse and disposal rate has been maintained at a high level and improved a lot than the last 5 years.
\end{abstract}

关键词: 包头; 危险废物; 产生; 利用; 处置

Keywords : BaoTou; Hazardous waste; generation ; Reuse ; Disposal

DOI : $10.36012 /$ etr.v2i12.3061

包头市作为全国的重点重工业城市,危险废物产生数量 医疗废物不在此次分析范围内。

很大,2016-2020 年期间增长明显, 随着国家对危险废物分

类更加细化, 纳人危险废物管理的数量也越来越多,2019 年

产生危险废物产生量已经相当于在全国大中城市排名第三

[1]。本文选取包头市 2016-2020 年期间固废申报数据中的工 业危险废物申报数据, 进行了逐年对比, 并与上个 5 年 (2010-2015 年)进行对比, 得出包头市危险废物变化趋势及 去向等数据分析。

\section{1.数据来源}

“十二五”期间数据来源于《包头市环境质量报告书》 （2011-2015 年 ),2016-2020 年期间数据来源于内蒙古生态 环境厅开发的“内蒙古自治区固体废物信息管理系统”, 其中 2016-2019 年数据来源于一次性的年报申报, 2020 年数据来 源于日常出人库、电子转移联单等动态数据进行汇总导出,

\subsection{0 年情况}

\section{1 产生情况}

2020 年，包头市 230 家单位产生工业危险废物 169.24 万吨, 占全国 2019 年[1]总产生量的 $3.8 \%$ 。全市各旗县区分 布不均衡, 其中九原区和昆区最多,九原达到 100 万吨以上, 占全市的 $67.7 \%$, 昆区有 40 万吨以上, 占 $23.6 \%$, 东河、高 新、固阳在 1 吨以上, 共占 $6.5 \%$, 其他 6 个旗县区产生量不 到 1 吨,共占 $0.02 \%$ 。

2020 年包头市产生的工业危险废物根据《国家危险废 物名录》(2016 年版) ${ }^{[2]}$ 可划分 23 大类, 前 5 类分别是: HW 33 无机氰化物废物、HW11 精(蒸)馏残渣、HW48 有色金属冶炼 废物、HW34 废酸和 HW18 焚烧处置残渣。前五类占总体的 $99.3 \%$,其他 18 类占总体的 $0.7 \%$ 。工业危险废物主要类别见

【作者简介】刘叶(1985 ), 女, 汉族, 内蒙古乌兰察布人,环境保护工程师, 工程硕士, 研究方向: 固体废物管理。 
图 1。

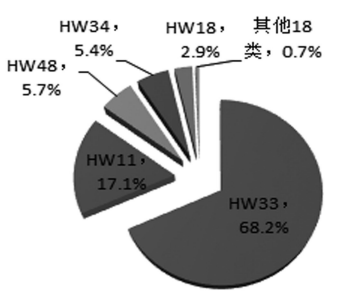

图 1 包头市 2020 年工业危险废物主要类别

\subsection{0 年去向}

2020 年工业危险废物利用处置量为 168.45 万吨，利用 处置率为 $99.5 \%$; 2020 年工业危险废物累计咜存量为 4.65 万吨。

\section{$3.2016-2020$ 年期间变化及与上个 5 年对比}

\section{$3.12016-2020$ 年期间变化}

2016-2020 年,包头市工业危险废物产生总量为 505.41 万吨, 利用处置 500.04 万吨, 利用处置率 $98.9 \%$ 。

2016 年-2020 年, 包头市工业危险废物产生量逐年增 长, 2017 年到 2018 年增长明显, 2016-2020 年危险废物利用 处置率均高于 95\%,2019-2020 年达到 99\%以上。2016-2020 年工业危险废物变化趋势情况见图 2 。

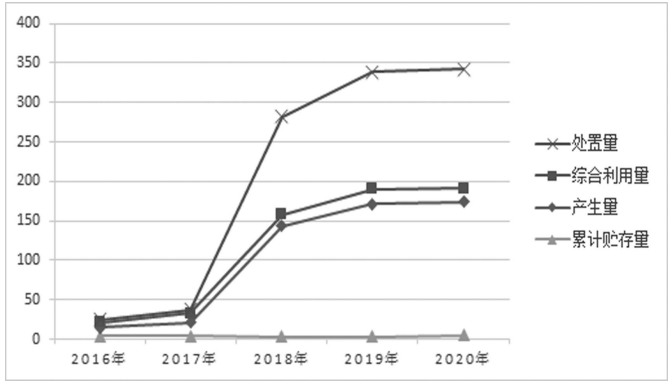

图 2 2016-2020 年包头市工业危险废物变化趋势

\section{2 与 2010-2015 年对比}

2010-2015 年, 危险废物产生量为 19.55 万吨, 利用处置 量为 17.60 万吨, 利用处置率为 $90 \%$; 咜存量为 1.95 万吨, 咜 存率为 10\%。2016-2020 年产生量增长 485.86 万吨, 增长 24.9 倍; 利用处置量增加 482.44 万吨, 综合利用量增长 27.4 倍, 利用处置率增加 8.9 个百分点; 咜存量增加 3.42 万吨, 咜 存量增长 1.75 倍。

\section{4.结论及原因分析}

\section{1 结论}

2016-2020 年期间,工业危险废物产生量逐年递增, 2017 年到 2018 年有显著增长, 2016-2020 年产生量较上个 5 年增长约 30 倍; 危险废物利用处置率一直保持在较高水 平, 且呈逐年提升趋势, 整体较上个 5 年有明显提升。

\section{2 原因分析}

2016-2020 年,工业危险废物产生量逐年递增是因为随 着国民经济不断发展, 产生危险废物的企业数量和规模都在 不断提升, 2017 年到 2018 年有明显增长是因为 2016 年制定 的《国家危险废物名录》将黄金行业的含氰尾渣列为危险废 物, 而包头的金矿企业产生的黄金尾渣数量庞大, 对整体产 生量影响较明显。危险废物利用处置率较上个 5 年有明显 提升, 主要原因一是相关部门和单位越来越重视危险废物的 管理,新《固废法》等一系列更严格的法律法规相继出台, 监 管部门更加专业和严格,企业自身也对环保要求越来越高； 二是在“无废城市”等地方政策和规划的推动下,包头市从

“十二五”期间的 3 家危险废物经营单位到现在已发展到 18 家危险废物经营单位, 产生企业转移危险废物更加方便快 捷。同时随着《包头市危险废物利用处置规划(2021-2025 年)》的印发, 规划全市建设危险废物利用处置设施 8 个, 也 将进一步扩大包头市危险废物利用处置能力。

\section{参考文献}

[1] 2020 年全国大、中城市固体废物污染环境防治年报[J].中国资 源综合利用,202 1,39(01):4.

[2] 国家危险废物名录[J].中华人民共和国国务院公报,2016(26): 39-40.

[3] 赵斌,史易,王海燕,徐永明,燕小凤,赵斌,塔娜,赵菊芳,王晓晖.危 险废物管理现状[J].环境与发展,2019,31(12):239-240.

[4] 刘翠玲.包头市推进国家“无废城市”建设试点的研究[J].中国资 源综合利用,2020,38(11):43-45. 